Jurnal Teori dan Praksis Pembelajaran IPS, Volume 5, No. 2, Tahun 2020, Hal 79-91

http://dx.doi.org/10.17977/um022v5i22020p79

P-ISSN: 2503-1201; E-ISSN: 2503-5347

\title{
Pemetaan Sebaran Dan Deskripsi Potensi Obyek Wisata Umbul Di Kabupaten Klaten
}

\author{
Kunthum Ria Anggraheny \\ Fakultas Keguruan dan Ilmu Pendidikan, Universitas Widya Dharma \\ Klaten, Indonesia \\ kunthumria@unwidha.ac.id \\ Nevy Farista Aristin \\ Fakultas Keguruan dan Ilmu Pendidikan, Universitas Lambung Mangkurat \\ Banjarmasin, Indonesia \\ nevyfarista@ulm.ac.id \\ Norma Yuni Kartika \\ Fakultas Ilmu Sosial dan Ilmu Politik, Universitas Lambung Mangkurat \\ Banjarmasin, Indonesia \\ norma.kartika@ulm.ac.id
}

\begin{abstract}
Tourism is an important sector in improving the economy of a region. Klaten Regency is known as 1001 umbul regency, of which the umbul tourism object is spread over 26 districts. This study aims to identify the distribution and potential of umbul tourism objects in Klaten Regency. This research is a quantitative approach with survei method, using spatial analysis, namely GIS and analysis of scoring and classification. Based on the results of this study, the distribution of umbul tourism objects in Klaten Regency is spread over seven districts, which form a straight line and are still in one aquifer network. The internal potential have high value, namely Umbul Brintik, Susuhan, Pelem, and Ponggok. The high external factors are owned by Umbul Susuhan, Ponggok, and Pelem. The potential for a combination of internal and external factors with a high value is owned by Umbul Brinta, Susuhan, Pelem, and Ponggok. Umbul Gedaren and Jolotundo still have moderate potential. Umbul Gedaren and Jolotundo still need to improve every element in internal and external factors so that these two tourism objects can be develop optimally. The potential of this umbul tourism object, if it is developed optimally, will later be useful for the people around the tour which can later improve the economy and welfare of the community.
\end{abstract}

Keywords: Distribution, Potential, Tourism, Umbul

\begin{abstract}
Abstrak
Pariwisata merupakan sektor penting dalam peningkatan perekonomian suatu daerah. Kabupaten Klaten terkenal dengan sebutan Kabupaten 1001 umbul, yang mana obyek wisata umbul tersebar di 26 kecamatan. Penelitian ini bertujuan untuk mengidentifikasi sebaran dan potensi obyek wisata umbul di Kabupaten Klaten. Penelitian ini menggunakan pendekatan kuantitatif dengan metode survei dan menggunakan analisis keruangan yaitu GIS dan analisis skoring dan klasifikasi. Berdasarkan hasil penelitian ini bahwa persebaran obyek wisata umbul di Kabupaten Klaten tersebar di tujuh kecamatan, yang membentuk satu garis lurus dan masih dalam satu
\end{abstract}




\section{Kunthum Ria Anggraheny, Nevy Farista Aristin, dan Norma Yuni Kartika}

jaringan akuifer. Potensi internal yang tinggi dimiliki oleh beberapa umbul yaitu Umbul Brintik, Susuhan, Pelem, dan Ponggok, sedangkan faktor eksternal yang tinggi dimiliki oleh Umbul Susuhan, Ponggok, dan Pelem. Potensi gabungan faktor internal dan eksternal dengan nilai ting gi ini dimiliki oleh Umbul Brintik, Susuhan, Pelem, dan Ponggok, sedangkan Umbul Gedaren dan Jolotundo masih berpotensi sedang. Umbul Gedaren dan Jolotundo masih perlu ditingkatkan tiap unsur yang ada di faktor internal dan eksternal sehingga kedua obyek wisata ini dapat berkembang secara optimal. Potensi obyek wisata umbul ini apabila dikembangkan secara optimal nantinya dapat bermanfaat bagi masyrakat yang ada di sekitar wisata tersebut yang nantinya dapat meningkatkan perekonomian dan kesejahteraan masyarakat.

Kata Kunci: Sebaran, Potensi, Wisata, Umbul

Diterima tgl bulan tahun, Dipublikasikan tgl bulan tahun

\section{PENDAHULUAN}

Kabupaten Klaten yang merupakan salah satu kabupaten yang ada di Jawa Tengah mempunyai potensi kekayaan alam, seperti sektor pertanian, perkebunan dan perikanan, industri serta pariwisata. Sektor pariwisata saat ini merupakan sektor unggulan dalam menunjang perekonomian suatu wilayah. Suatu wilayah memiliki potensi pariwisata yang mana harus mampu menyediakan, mengolah, mengembangkan, hingga mempromosikan wisata kepada orang lain (Sujali, 1989).

Kabupaten Klaten memiliki banyak jenis wisata antara lain wisata budaya (situs candi, museum, serta cagar budaya lainnya), wisata alam (wisata air, wisata pegunungan). Pariwisata yang sedang dikembangkan yaitu wisata alam berbasis air. Oleh karena itu, Kabupaten Klaten memiliki julukan "Kabupaten Seribu Satu Umbul", sehingga menjadikan daya tarik yang berbeda dengan daerah lain bagi wisatawan domestik hingga mancanegara untuk melakukan aktivitas wisata di Kabupaten Klaten. Tetapi pada kenyataannya, tidak semua obyek wisata umbul dikunjungi dan diminati oleh para wisatawan bahkan terdapat umbul yang belum dimanfaatkan secara optimal. Umbul yang belum dimanfaatkan ini biasanya digunakan untuk pemenuhan kebutuhan air dan irigasi untuk aktivitas masyarakat.

Faktor penyebab obyek wisata umbul belum dimanfaatkan secara optimal untuk sektor pariwisata dikarenakan (1) obyek wisata umbul yang ada di Kabupaten Klaten belum seluruhnya dikenal oleh masyarakat, (2) kurangnya informasi terkait obyek wisata umbul di Kabupaten Klaten, (3) ketersediaan sarana dan prasarana penunjang obyek wisata umbul belum memadai, (4) aksesibilitas menuju obyek wisata masih terbatas, terutama obyek wisata yang letaknya jauh dari jalan raya, dan (5) pengelolaan obyek wisata umbul masih bercorak tradisional dan peran masyarakat yang belum optimal.

Saat ini adalah era revolusi industri 4.0 yang mana inovasi teknologi berkembang sangat cepat (Aristin, Budijanto, Taryana, \& Ruja, 2019) baik dalam pendidikan maupun non pendidikan termasuk sektor pariwisata. Peta sebaran obyek wisata ini diperoleh dari olah data dengan menggunakan aplikasi Sistem Informasi Geografi (SIG). SIG di era digital seperti sekarang, sangat bermanfaat dalam penyajian informasi terkait obyek wisata termasuk potensi wisata beserta fasilitas yang ada di obyek wisata. Potensi wisata merupakan aspek penting yang dimiliki obyek wisata guna menarik wisatawan agar berkunjung ke obyek wisata tersebut (Yoeti, 1998). 


\section{Pemetaan Sebaran dan Deskripsi Potensi Obyek Wisata Umbul di Kabupaten Klaten}

Salah satu cara dalam optimalisasi obyek wisata umbul yaitu dengan cara meningkatkan informasi terkait obyek wisata umbul yang ada di Kabupaten Klaten. Penyampaian informasi dapat dilakukan dengan cara adanya peta persebaran obyek wisata umbul di Kabupaten Klaten. Peta di bidang pariwisata yang dalam pembuatannya menggunakan SIG yang sesuai dengan era digital seperti sekarang ini dapat mengetahui potensi wilayah yang berpengaruh terhadap sosial kultural yang nantinya dapat mendukung sektor pariwisata (Soekidjo, 1994). Peta ini dapat berfungsi sebagai media yang memberikan informasi tentang obyek wisata kepada masyarakat atau wisatawan. Pada dasarnya peta merupakan sebagai alat untuk berkomunikasi tentang suatu informasi yang diberikan kepada khalayak umum tentang kondisi suatu wilayah (Farid, Wahidiyat, Andayani, Harifuddin, \& Salam, 2017). Selain itu juga, dengan penggunaan aplikasi SIG dapat mengembangkan potensi obyek wisata umbul yang ada di Kabupaten Klaten.

Dengan adanya obyek wisata umbul yang menjadi icon penting Kabupaten Klaten yang masih belum optimal dalam pemanfaatannya, bahkan masyarakat belum mengetahui potensinya secara menyeluruh serta tidak adanya informasi yang lengkap dan akurat terkait ini, maka diperlukan suatu cara dalam pengembangan obyek wisata umbul dengan mengidentifikasi persebaran lokasi obyek wisata umbul yang ada di Kabupaten Klaten. Perkembangan obyek wisata dapat berkembang secara optimal apabila dimulai dengan mengidentifikasi persebaran lokasi obyek wisata umbul dan disajikan berupa peta. Ini masih belum ada penelitian terkait yang dilakukan di Kabupaten Klaten sehingga diperlukan adanya identifikasi persebaran dan potensi obyek wisata umbul di Kabupaten Klaten yang mana hal ini sebagai kunci dari perkembangan pariwisata berbasis air.

\section{METODE}

Penelitian ini menggunakan pendekatan kuantitatif dengan metode survei. Lokasi penelitian ini dilakukan di Kabupaten Klaten. Populasi penelitian ini ada tujuh kecamatan yang mempunyai obyek wisata umbul. Teknik pengambilan sampel menggunakan purposive sampling sehingga satu kecamatan dapat diwakili oleh satu obyek wisata umbul. Penelitian ini dengan menggunakan observasi lapangan yang bertujuan untuk mengetahui kondisi obyek wisata secara langsung, meliputi kondisi fisik obyek wisata, fasilitas yang ada, dan aksesibilitas menuju lokasi obyek wisata. Variabel penelitian yang digunakan dapat dilihat pada tabel 1.1 sebagai berikut.

Tabel 1 Variabel Penelitian

\begin{tabular}{lll}
\hline \multicolumn{1}{c}{ Variabel } & \multicolumn{1}{c}{ Indikator } & \multicolumn{1}{c}{ Sub Indikator } \\
\hline Potensi Internal & a. Daya Tarik Obyek Wisata & 1. Keunikan \\
& & 2. Keragaman Atraksi \\
& b. Debit Air & 3. Kebersihan Lingkungan \\
& a. Aksesibilitas & 4. Potensi Pengembangan \\
Potensi Eksternal & & \\
& & 1. Lokasi \\
& b. Fasilitas Pendukung & 2. Aksesibilitas \\
& & 3. Kondisi Jalan \\
& c. Pasar & 4. Rambu - Rambu Penunjuk Lokasi \\
& & 1. Kondisi sarana dan prasarana \\
& & 2. Kelengkapan sarana dan prasarana \\
\end{tabular}


Kunthum Ria Anggraheny, Nevy Farista Aristin, dan Norma Yuni Kartika

\begin{tabular}{|c|c|c|}
\hline Variabel & Indikator & Sub Indikator \\
\hline & $\begin{array}{l}\text { d. Dampak Pengembangan terhadap } \\
\text { Ekonomi dan Lingkungan Sekitarnya }\end{array}$ & $\begin{array}{l}\text { 2. Tingkat kunjungan } \\
\text { 3. Promosi dan informasi } \\
\text { 1. Sistem pengelolaan } \\
\text { 2. Sumberdaya Manusia } \\
\text { 3. Dampak ekonomi sosial } \\
\text { 4. Dampak lingkungan }\end{array}$ \\
\hline
\end{tabular}

Metode penelitian yang digunakan dengan cara pengolahan data berupa skoring dan pengklasifikasian. Klasifikasi bertujuan untuk menentukan kelas potensi obyek wisata dengan cara menentukan interval kelas dengan menggunakan rumus Sturges (Prihandoko, 2008) sebagai berikut.

Keterangan:

$$
K=\frac{\mathrm{a}-\mathrm{b}}{\mathrm{u}}(1)
$$

$\mathrm{K}=$ Klasifikasi

$\mathrm{a}=$ nilai skor tertinggi

$\mathrm{b}=$ nilai skor terendah

$\mathrm{u}=$ jumlah kelas.

Klasifikasi ini digunakan untuk menentukan potensi internal, eksternal, dan gabungan obyek wisata. Hasil dari rumus di atas maka dibedakan menjadi tiga klasifikasi dengan kelas potensi tinggi, sedang, dan rendah.

\section{HASIL DAN PEMBAHASAN}

\section{Persebaran Obyek Wisata Umbul di Kabupaten Klaten}

Peta Persebaran umbul di Kabupaten Klaten terdapat di 7 kecamatan, yang terdapat sekitar 13 umbul. 13 umbul tersebut yang pemanfaatannya sebagai obyek pariwisata, antara lain Umbul Tempel, Pluneng, Brintik, Brondong, Gedaren, Susuhan, Jolotundo, Ponggok, Kapilaler, Ingas, Bale Kambang, Nilo, Pelem, Manten. Umbul tersebut tersebar di 7 kecamatan di Kabupaten Klaten. Persebaran obyek wisata umbul yang mewakili tujuh kecamatan di Kabupaten Klaten yang dimanfaatkan sebagai obyek wisata, sebagai berikut.

Tabel 2 Lokasi Obyek Wisata Umbul Kabupaten Klaten

\begin{tabular}{|c|c|c|}
\hline No & Nama Umbul & Lokasi \\
\hline 1 & Ipik & Dk. Ipik, Ds. Daguran, Kec. Klaten Selatan \\
\hline 2 & Pluneng & Dk. Karang Lor, Ds. Pluneng, Kec. Kebonarum \\
\hline 3 & Brintik & Dk. Brintik, Ds. Malang Jiwan, Kec. Kebonarum \\
\hline 4 & Brondong & Dk. Ngrundul, Ds. Ngrundul, Kec. Kebonarum \\
\hline 5 & Kapilaler & Dk. Banjar Rejo, Ds. Karanglo, Kec. Polanharjo \\
\hline 6 & Nganten & Dk. Janti, Ds. Janti, Kec. Polanharjo \\
\hline 7 & Pelem & Dk. Wunut, Ds. Wunut, Kec. Tulung \\
\hline 8 & Ingas & Dk. Cokro Kembang, Ds. Daleman, Kec. Tulung \\
\hline 9 & Bale Kambang & Dk. Cokro Kembang, Ds. Daleman, Kec. Tulung \\
\hline 10 & Nilo & Dk. Margosuko, Ds. Daleman, Kec. Tulung \\
\hline 11 & Gedaren & Dk. Gedaren, Ds. Gaderan, Kec. Jatinom \\
\hline 12 & Jolotundo & Dk. Surabayan, Ds. Jambeyan, Kec. Karanganom \\
\hline 13 & Ponggok & Dk. Ponggok, Ds. Ponggok, Kec. Karanganom \\
\hline 14 & Susuhan & Dk. Susuhan, Ds. Manjungan, Kec. Ngawen \\
\hline
\end{tabular}

Sumber: Hasil Olah Data Primer, 2019 


\section{Pemetaan Sebaran dan Deskripsi Potensi Obyek Wisata Umbul di Kabupaten Klaten}

Hasil olah data primer tentang persebaran obyek wisata umbul di tujuh kecamatan Kabupaten Klaten disajikan dalam bentuk peta yang dibantu olah datanya dengan ArcGIS. Hasil peta persebaran obyek wisata tersebut dapat dilihat pada gambar 1 sebagai berikut.

Berdasarkan hasil peta persebaran obyek wisata umbul di Kabupaten Klaten didapatkan bahwa umbul terbanyak berada di Kecamatan Tulung sebanyak 4 umbul dan Kecamatan Kebonarum mempunyai umbul sebanyak 3 umbul, dan umbul lainnya terbesar di beberapa kecamatan lainnya. Ini dapat digunakan sebagai pedoman dalam pengembangan pariwisata secara optimal. Lokasi yang strategis di Kecamatan Tulung dan Kebonarum bisa dijadikan aspek penting dalam pertimbangan untuk peningkatan kualitas obyek wisata di Kabupaten Klaten. Ini sesuai dengan pernyataan bahwa lokasi merupakan salah satu faktor sumberdaya pariwisata yang berperan dominan dalam pengembangan obyek wisata (Susanti, 2005; Pitana, 2009).

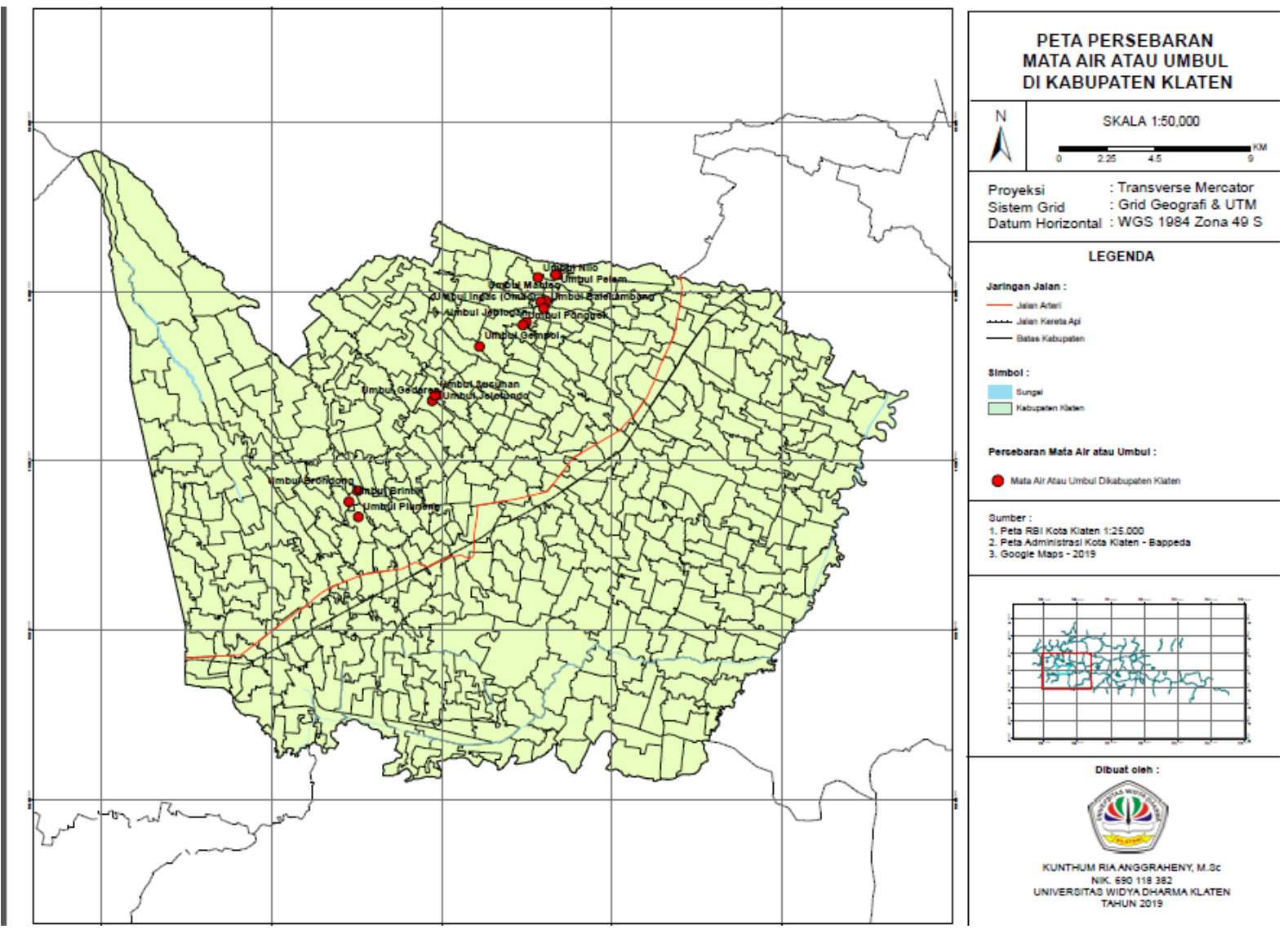

Gambar 1 Peta Persebaran Obyek Wisata Umbul di Kabupaten Klaten

\section{Potensi Internal Obyek Wisata Umbul di Kabupaten Klaten}

Obyek wisata memiliki suatu potensi internal yang mana potensi tersebut dapat dijadikan indikator terkait kondisi alamiah yang tidak dapat dikembangkan baik secara kualitas dan kondisi obyek wisatanya. Potensi internal obyek wisata yang ada di enam umbul, hasil klasifikasi potensi internalnya dapat dilihat pada tabel 3 sebagai berikut. 


\section{Kunthum Ria Anggraheny, Nevy Farista Aristin, dan Norma Yuni Kartika}

Berdasarkan hasil klasifikasi potensi internal obyek wisata umbul didapatkan bahwa sebagian besar umbul berpotensi tinggi yaitu Umbul Brintik, Susuhan, Ponggok, dan Pelem. Umbul Gedaren dan Jolotundo merupakan umbul yang mempunyai potensi internal dalam kategori sedang. Secara keseluruhan umbul yang ada di Kabupaten Klaten mempunyai potensi yang baik untuk dikembangkan dengan ciri khas atau keunikan yang dimiliki oleh tiap umbul tersebut. Potensi internal yang dimiliki oleh umbul tersebut disajikan dalam bentuk peta potensi internal yang dapat dilihat pada gambar 2 .

Tabel 3 Potensi Internal Obyek Wisata Umbul di Kabupaten Klaten

\begin{tabular}{|c|c|c|c|c|c|c|c|}
\hline \multirow{3}{*}{$\begin{array}{l}\text { Obyek } \\
\text { Wisata } \\
\text { Umbul }\end{array}$} & \multicolumn{5}{|c|}{ Potensi Internal } & \multirow{3}{*}{$\begin{array}{l}\text { Total } \\
\text { Skor }\end{array}$} & \multirow{3}{*}{ Klasifikasi } \\
\hline & \multicolumn{4}{|c|}{ Daya Tarik Obyek Wisata } & \multirow[b]{2}{*}{$\begin{array}{l}\text { Debit } \\
\text { Air }\end{array}$} & & \\
\hline & Keunikan & $\begin{array}{c}\text { Keberagaman } \\
\text { Atraksi }\end{array}$ & $\begin{array}{l}\text { Kebersihan } \\
\text { Lingkungan }\end{array}$ & $\begin{array}{l}\text { Potensi } \\
\text { Lahan }\end{array}$ & & & \\
\hline Umbul Brintik & 3 & 3 & 2 & 2 & 2 & 12 & Tinggi \\
\hline $\begin{array}{l}\text { Umbul } \\
\text { Susuhan }\end{array}$ & 2 & 3 & 3 & 2 & 2 & 12 & Tinggi \\
\hline $\begin{array}{l}\text { Umbul } \\
\text { Gedaren }\end{array}$ & 2 & 2 & 1 & 2 & 2 & 9 & Sedang \\
\hline $\begin{array}{l}\text { Umbul } \\
\text { Jolotundo }\end{array}$ & 2 & 2 & 2 & 1 & 2 & 10 & sedang \\
\hline $\begin{array}{l}\text { Umbul } \\
\text { Ponggok }\end{array}$ & 3 & 3 & 3 & 3 & 2 & 14 & Tinggi \\
\hline Umbul Pelem & 3 & 3 & 3 & 3 & 1 & 13 & Tinggi \\
\hline
\end{tabular}

Sumber data: Data Primer, 2019

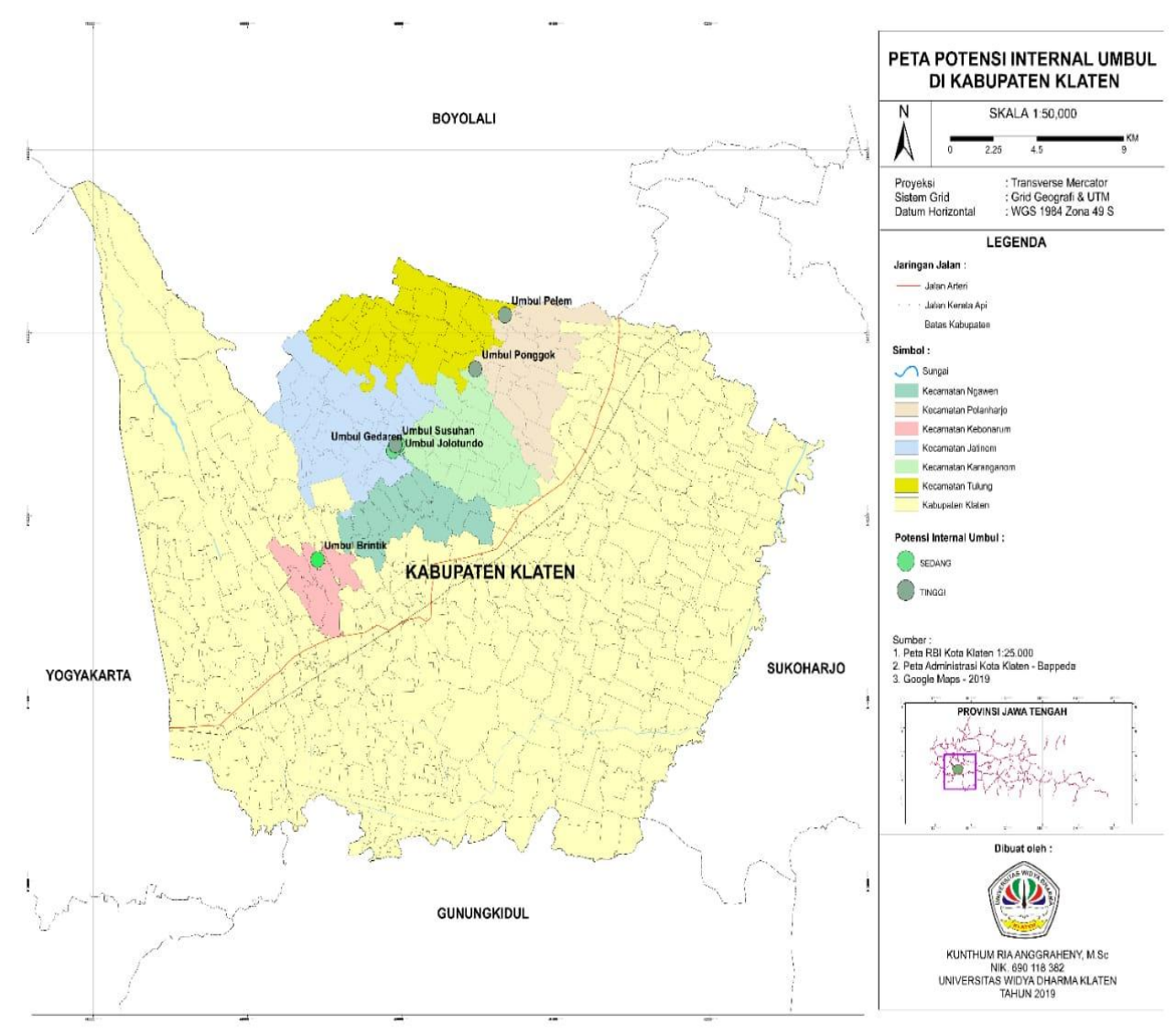

Gambar 2 Peta Potensi Internal Obyek Wisata Umbul di Kabupaten Klaten 


\section{Potensi Eksternal Obyek Wisata Umbul di Kabupaten Klaten}

Selain potensi internal, potensi eksternal dapat dilihat dari kondisi buatan yang ada di obyek wisata, meliputi lokasi dan aksesibilitas, fasilitas pendukung, pasar dan pemasaran, pengelolaan dan dampak terhadap kawasan sekitar obyek wisata. Analisis potensi eksternal obyek wisata umbul di Kabupaten Klaten dapat dilihat pada tabel 4.

Hasil klasifikasi pada potensi eksternal diketahui bahwa obyek wisata umbul di Kabupaten Klaten memiliki potensi mulai dari potensi rendah hingga tinggi. Potensi eksternal rendah ada pada Umbul Gedaren, sedangkan potensi ekternal obyek wisata umbul berkelas sedang ada di Umbul Brintik dan Jolotundo serta ada tiga umbul yang berpotensi tinggi ada di Umbul Susuhan, Ponggok, dan Pelem.

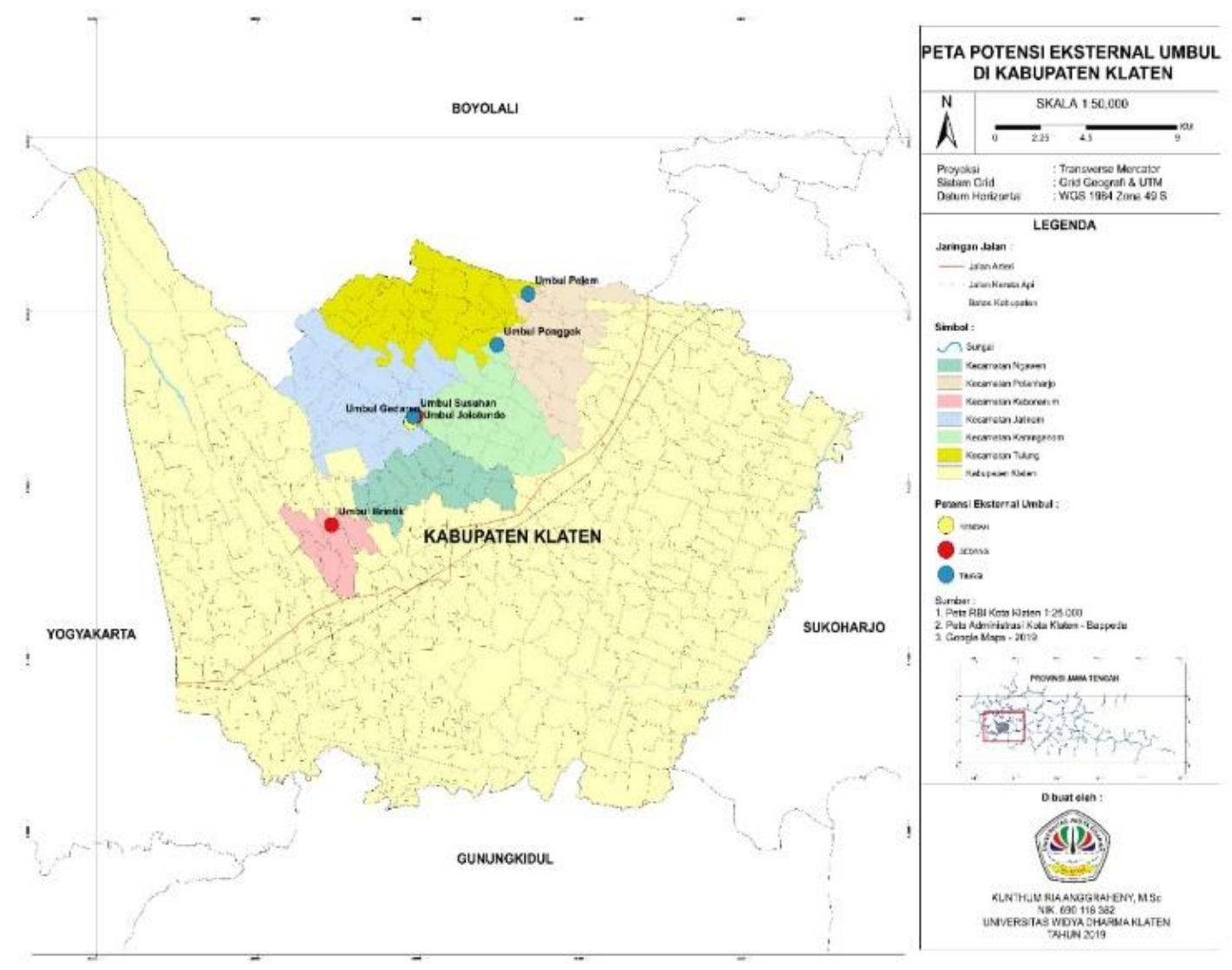

Gambar 3. Peta Potensi Eksternal Obyek Wisata Umbul Di Kabupaten Klaten

Umbul yang berpotensi tinggi ini dipengaruhi oleh trend pariwisata yang mana para wisatawan lebih tertarik dengan wisata bahari (air) dan mempunyai titik lokasi untuk foto yang instagramable. Ini menyebabkan tingkat kunjungan wisatawan semakin meningkat. Selain itu, obyek wisata umbul ini ditunjang dengan fasilitas yang mendukung seperti kondisi jalan yangsudah beraspal, adanya transportasi umum baik transporatasi konvesional maupun transportasi umum berbasis online. Obyek wisata umbul yang klasifikasi rendah dikarenakan beberapa faktor yaitu fasilitas masih minim, tingkat kunjungan dari wisatawan lokal saja. Pengembangan obyek wisata harus didukung 


\section{Kunthum Ria Anggraheny, Nevy Farista Aristin, dan Norma Yuni Kartika}

oleh komponen fasilitas, atraksi, dan aksesibilitas yang menjadi daya tarik suatu obyek wisata (Abdulhaji \& Yusuf, 2016). Obyek wisata Umbul Gedaren merupakan umbul yang berklasifikasi rendah, yang mulai dikembangkan pada akhir tahun 2018. Fasilitas yang ada di Umbul Gedaren masih minim sehingga masih perlu dikembangkan secara optimal. Ini nantinya dapat menjadi obyek wisata umbul yang potensial di Kabupaten Klaten yang tetap disesuaikan dengan kondisi fisik yang ada di sekitar Umbul Gedaren. Hasil klasifikasi potensi eksternal ini disajikan dalam bentuk peta sepeti yang ada di gambar 3 . 


\section{Pemetaan Sebaran dan Deskripsi Potensi Obyek Wisata Umbul di Kabupaten Klaten}

Tabel 4 Potensi Eksternal Obyek Wisata Umbul di Kabupaten Klaten

\begin{tabular}{|c|c|c|c|c|c|c|c|c|c|c|c|c|c|c|c|c|}
\hline \multirow{3}{*}{$\begin{array}{l}\text { Obyek } \\
\text { Wisata } \\
\text { Umbul }\end{array}$} & \multicolumn{14}{|c|}{ Potensi Eksternal } & \multirow{3}{*}{$\begin{array}{c}\text { Tota } \\
1 \\
\text { Sko } \\
\text { r }\end{array}$} & \multirow{3}{*}{$\begin{array}{c}\text { Klasifika } \\
\text { si }\end{array}$} \\
\hline & \multicolumn{4}{|c|}{ Lokasi Dan Aksesibilitas } & \multicolumn{3}{|c|}{ Fasilitas Pendukung } & \multicolumn{3}{|c|}{ Pasar Dan Pemasaran } & \multicolumn{4}{|c|}{$\begin{array}{c}\text { Pengelolaan Dan Dampak Terhadap } \\
\text { Kawasan Sekitar }\end{array}$} & & \\
\hline & & & & & & & & & & & & & & & & \\
\hline $\begin{array}{c}\text { Variabe } \\
1\end{array}$ & $\begin{array}{c}\text { Loka } \\
\text { si }\end{array}$ & $\begin{array}{l}\text { Aksesibilit } \\
\quad \text { as }\end{array}$ & $\begin{array}{l}\text { Kondi } \\
\text { si } \\
\text { Jalan }\end{array}$ & $\begin{array}{c}\text { Ramb } \\
\text { u- } \\
\text { Ramb } \\
\mathbf{u}\end{array}$ & $\begin{array}{l}\text { Kondi } \\
\text { si } \\
\text { Sarpr } \\
\text { as }\end{array}$ & $\begin{array}{l}\text { Kelengkap } \\
\text { an Sarpras }\end{array}$ & $\begin{array}{l}\text { Kapasit } \\
\text { as }\end{array}$ & $\begin{array}{c}\text { Skal } \\
\text { a } \\
\text { Pasa } \\
\mathbf{r}\end{array}$ & $\begin{array}{l}\text { Tingkat } \\
\text { Kunjung } \\
\text { an }\end{array}$ & $\begin{array}{c}\text { Promo } \\
\text { si }\end{array}$ & $\begin{array}{c}\text { Sistem } \\
\text { Pengelola } \\
\text { an }\end{array}$ & $\begin{array}{l}\text { SD } \\
\text { M }\end{array}$ & $\begin{array}{c}\text { Dampa } \\
\text { k } \\
\text { Ekono } \\
\text { mi } \\
\text { Sosial }\end{array}$ & $\begin{array}{c}\text { Dampak } \\
\text { Lingkung } \\
\text { an }\end{array}$ & & \\
\hline $\begin{array}{l}\text { Umbul } \\
\text { Brintik }\end{array}$ & 2 & 2 & 2 & 2 & 3 & 3 & 2 & 2 & 2 & 3 & 2 & 3 & 3 & 3 & 32 & Sedang \\
\hline $\begin{array}{l}\text { Umbul } \\
\text { Susuhan }\end{array}$ & 3 & 3 & 3 & 2 & 3 & 3 & 3 & 2 & 2 & 2 & 2 & 2 & 3 & 2 & 35 & Tinggi \\
\hline $\begin{array}{l}\text { Umbul } \\
\text { Gedaren }\end{array}$ & 3 & 3 & 3 & 1 & 2 & 2 & 2 & 1 & 1 & 1 & 1 & 1 & 1 & 1 & 23 & Rendah \\
\hline $\begin{array}{l}\text { Umbul } \\
\text { Jolotund } \\
\text { o }\end{array}$ & 3 & 3 & 3 & 2 & 3 & 2 & 2 & 2 & 2 & 1 & 1 & 1 & 2 & 2 & 29 & Sedang \\
\hline $\begin{array}{l}\text { Umbul } \\
\text { Ponggo } \\
\text { k }\end{array}$ & 2 & 2 & 3 & 3 & 3 & 3 & 3 & 3 & 3 & 3 & 3 & 3 & 3 & 3 & 40 & Tinggi \\
\hline $\begin{array}{l}\text { Umbul } \\
\text { Pelem }\end{array}$ & 2 & 2 & 3 & 2 & 3 & 3 & 3 & 2 & 2 & 2 & 3 & 2 & 3 & 3 & 35 & Tinggi \\
\hline
\end{tabular}

Sumber data: Data Primer, 2019 


\section{Kunthum Ria Anggraheny, Nevy Farista Aristin, dan Norma Yuni Kartika}

\section{Potensi Gabungan Obyek Wisata Umbul di Kabupaten Klaten}

Potensi gabungan ini merupakan potensi yang dilihat dari faktor internal dan eksternal dari suatu obyek wisata, khususnya dalam penelitian ini adalah obyek wisata umbul di Kabupaten Klaten. Selanjutnya, hasil dari keseluruhan kedua faktor ini dihitung secara sistematis dan diklasifikasikan menjadi kelas rendah, sedang, dan tinggi. Analisis ini bertujuan untuk mempermudah dalam mengetahui potensi umbul secara keseluruhan sebagai obyek wisata yang dapat dikembangkan oleh pemerintah dan masyarakat di Kabupaten Klaten. Hasil potensi gabungan dari potensi internal dan eksternal obyek wisata umbul di Kabupaten Klaten dapat dilihat pada tabel 5 .

Tabel 5 Potensi Gabungan Obyek Wisata Umbul di Kabupaten Klaten

\begin{tabular}{clcccc}
\hline No. & Obyek Wisata Umbul & Potensi Internal & Potensi Eksternal & Jumlah Skor & Klasifikasi \\
\hline 1 & Brintik & 12 & 32 & 44 & Tinggi \\
2 & Susuhan & 12 & 35 & 47 & Tinggi \\
3 & Gedaren & 9 & 23 & 32 & Sedang \\
4 & Jolotundo & 10 & 29 & 39 & Sedang \\
5 & Ponggok & 14 & 40 & 54 & Tinggi \\
6 & Pelem & 13 & 35 & 48 & Tinggi \\
\hline
\end{tabular}

Sumber: Data Primer, 2020

Berdasarkan hasil data olah primer dalam analisis gabungan antara potensi internal dan eksternal pada suatu obyek wisata di Kabupaten Klaten diketahui bahwa obyek wisata umbul yang berpotensi tinggi meliputi Umbul Brintik, Susuhan, Ponggok, dan Pelem. Selain itu, Umbul Gedaren dan Jolotundo diklasifikasikan obyek wisata mempunyai potensi gabungan kelas sedang. Umbul Gedaren dan Jolotundo ini masih dapat dikembangkan potensinya baik internal maupun eksternal sehingga nantinya menjadi obyek wisata yang unggul seperti umbulumbul lainnya.

Umbul Gedaren merupakan umbul yang ada di Kecamatan Gedaren dan Umbul Jolotundo yang ada di Desa Jambeyan Kecamatan Karanganom Kabupaten Klaten yang mempunyai potensi gabungan eksternal dan internal tingkat sedang. Umbul Gedaren dan Jolotundo mempunyai faktor eksternal yang dapat ditingkatkan untuk menjadi potensi yang dikembangkan di Umbul Gedaren dan Jolotundo ini meliputi pemasaran (promosi), sistem pengelolaan, dan sumberdaya manusianya. Promosi merupakan unsur penting dalam meningkatkan kunjungan wisatawan melalui media cetak maupun elektronik tetapi pemilihan media harus disesuaikan dengan target pasar yang dituju (Wolah, 2016). Untuk itulah, diperlukan promosi wisata untuk memperkenalkan obyek wisata ke seluruh Indonesia. Tanpa adanya promosi Umbul Gedaren dan Jolotundo maka tingkat kunjungan wisatawan tetap rendah. Selain promosi, aspek yang perlu ditingkatkan adalah sistem pengelolaan obyek wisata. Sistem pengelolaan pariwisata didasarkan pada perencanaan, pengorganisasian, penggerakan, dan pengendalian yang bertujuan untuk menjaga keberlangsungan obyek wisata yang ada sehingga dapat menyeimbangkan pertumbuhan dan pendapatan ekonomi dengan pelayanan yang diberikan kepada wisatawan serta untuk menjaga dan melestarikan obyek wisata 


\section{Pemetaan Sebaran dan Deskripsi Potensi Obyek Wisata Umbul di Kabupaten Klaten}

(Prasetyo, 2016; Datukramat, Veronika-Kumurur, \& Sela, 2017). Sistem pengelolaan pada Umbul Gedaren dan Jolotundo ini dapat ditingkatkan dan melibatkan kerjasama antar berbagai pihak. Sistem pengelolaan obyek wisata ini juga didasarkan pada keberadaan sumberdaya manusia (SDM) yang dimiliki oleh obyek wisata Umbul Gedaren dan Jolotundo. SDM pariwisata ini merupakan faktor penggerak keberlangsungan dari industri pariwisata (Setiawan, 2016). Untuk itulah SDM pariwisata ini perlu ditingkatkan dengan melalui pendidikan, pelatihan, dan pembinaan (Silalahi, 2000). Pendidikan, pelatihan, dan pembinaan tersebut untuk masyarakat yang bekerja di Umbul Gedaren untuk meningkatkan keterampilannya sehingga dapat menunjang keberhasilan dalam pengembangan pariwisata Umbul Gedaran dan Jolotundo di Kabupaten Klaten.

Potensi internal yang perlu ditingkatkan pada umbul Gedaren ini adalah terkait kebersihan lingkungan. Kebersihan lingkungan merupakan salah satu unsur faktor penting untuk keberlangsungan obyek wisata yang bersih, sehat, dan nyaman bagi wisatawan dalam menikmati suatu obyek wisata (Gromang, 2005; Wiseza, 2017). Kebersihan lingkungan yang ada di Umbul Gedaren ini merupakan tanggung jawab dan kesadaran dari semua pihak mulai dari masyarakat, pedagang, pemerintah, dan wisatawan itu sendiri. Selain itu juga, perlu ditingkatkan jumlah alat kebersihan seperti tempat sampah yang disediakan di sekitar obyek wisata Umbul Gedaren ini. Dengan lingkungan obyek wisata yang bersih ini dapat mempengaruhi keputusan wisatawan dalam berkunjung ke obyek wisata Umbul Gedaren. Ini didukung dengan pernyataan bahwa wisatwan sebelum melakukan perjalanan wisata, mereka terlebih dahulu mencari informasi tentang fasilitas dan keadaan lingkungan obyek wisata yang dituju sehingga mereka dapat mengambil keputusan untuk mengunjungi tujuan obyek wisata yang diinginkan (Yoeti, 1998).

Umbul Jolotundo masih dapat ditingkatkan untuk menjadi umbul yang berpotensi dalam obyek wisata air di Kabupaten Klaten. Aspek yang perlu ditingkatkan adalah potensi pengembangan dalam menata lahan yang ada di dalam obyek wisata Umbul Jolotundo. Umbul ini masih belum tertata dan adanya keterbatasan lahan. Ini mengakibatkan pengelola internal mengalami kesulitan dalam mengembangkan obyek wisata ini. Untuk itulah, diperlukan penataan kawasan wisata yang dengan potensi baik internal maupun eksternal yang dimiliki oleh Umbul Jolotundo. Tujuan penataan lahan obyek wisata ini sebenarnya untuk menciptakan kawasan wisata yang representative di Umbul Jolotundo sehingga wisatawan yang berkunjung nantinya merasa nyaman dalam menikmati obyek wisata ini. Tetapi, yang harus diperhatikan bahwa dalam penataan kawasan wisata Umbul Jolotundo ini harus berdasarkan pada keseimbangan dan saling ketergantungan lingkungan, ekonomi, dan sosial sehingga nantinya dapat terpelihara sumberdaya wisata baik alam maupun buatan manusia dalam jangka panjang (Dowling \& Fennell, 2010). 


\section{Kunthum Ria Anggraheny, Nevy Farista Aristin, dan Norma Yuni Kartika}

\section{KESIMPULAN}

Kabupaten Klaten yang disebut dengan Kabupaten 1001 umbul, yang tersebar di tujuh kecamatan yaitu Kecamatan Kebonarum, Karangmoko, Ngawen, Jatinom, Karanganom, Polanharjo, dan Jolotundo. Persebaran lokasi umbul membentuk satu garis lurus dan masih dalam satu jaringan aquifer. Umbul-umbul yang ada di Kabupaten Klaten ini diketahui mempunyai potensi baik internal, eksternal maupun gabungan dari kedua potensi tersebut. Hasil analisis didapatkan bahwa obyek wisata umbul antara lain Umbul Brintik, Susuhan, Ponggok, dan Pelem mempunyai potensi internal yang tinggi, sedangkan potensi eksternal yang tinggi ada pada Umbul Susuhan, Ponggok, dan Pelem. Potensi gabungan, di mana menggabungkan potensi internal dan eksternal, yang termasuk dalam klasifikasi potensi tinggi dimiliki oleh Umbul Brintik, Susuhan, Ponggok, dan Pelem. Sedangkan potensi gabungan Umbul Gedaren dan Jolotundo masih berpotensi sedang, yang mana diperlukan peningkatan di beberapa unsur potensi internal dan eksternal obyek wisata.

Rekomendasi dalam pengembangan obyek wisata umbul di Kabupaten Klaten yaitu agar meningkatkan promosi tiap obyek wisata umbul baik melalui media cetak maupun elektronik, meningkatkana keterlibatan masyarakat maupun pemerintah dalam sistem pengelolaan obyek wisata dan meningkatkan kualitas sumberdaya manusia dengan cara melalui pendidikan, pelatihan, dan pelatihan.

\section{DAFTAR PUSTAKA}

Abdulhaji, S., \& Yusuf, I. H. (2016). Pengaruh Atraksi, Aksesibilitas, dan Fasilitas Terhadap Citra Objek Wisata Danau Tolire Besar Di Kota Ternate. Jurnal Penelitian Humano, 134148.

Aristin, N. F., Budijanto, Taryana, D., \& Ruja, I. N. (2019). 3D Map of Dry Land Use Based

Aerial Image as Learning Media in Era of Education 4.0. International Journal of Emerging Technologies in Learning, 171-179.

Datukramat, H. P., Veronika-Kumurur, \& Sela, R. L. (2017). Faktor-Faktor Penyebab Tidak Terkelolanya Objek Wisata Pnatai Batu Pinagut Bolaang Mongondow Utara. Spasial: Perencanaan Wilayah Dan Kota, 4(1).

Dowling, R., \& Fennell, D. (2010). The Context of Tourism Policy and Planning. CAB International Journal, 1-20.

Farid, S., Wahidiyat, A., Andayani, D. D., Harifuddin, \& Salam, R. (2017). Pengembangan Daya Tarik Wisata Melalui Perancangan Peta Wisata Pantai Berbasis Google SketchUp. Jurnal Pekommas, 185-192.

Gromang, F. (2005). Tuntutan Keselamatan dan Keamanan Wisatawan. Jakarta: Pradnya Paramita.

Pitana, I. G. (2009). Pengantar Ilmu Pariwisata. Yogyakarta: ANDI.

Prasetyo, A. (2016). Faktor-Faktor Yang Mempengaruhi Keputusan Wisatwan Dalam Berkunjung Ke Obyek Wisata Gajah Mungkur Wonogiri. Surakarta: Skripsi. Universitas Sebelas Maret. 


\section{Pemetaan Sebaran dan Deskripsi Potensi Obyek Wisata Umbul di Kabupaten Klaten}

Prihandoko, A. (2008). Potensi Obyek Wisata Alam Di Kabupaten Semarang. Surakarta: Universitas Muhammadiyah Surakarta.

Setiawan, R. I. (2016). Pengembangan Sumber Daya Manusia Di Bidang Pariwisata: Perspektif Potensi Wisata Daerah Berkembang. Jurnal Penataran, 1(1).

Silalahi, B. (2000). Manajemen Sumberdaya Manusia. Jakarta: Sekolah Tinggi Ilmu Manajemen LPMI.

Soekidjo. (1994). Pengembangan Potensi Wilayah. Bandung: Gramedia.

Sujali. (1989). Geografi Pariwisata dan Kepariwisataan. Yogyakarta: BPFG UGM.

Susanti, I. U. (2005). Tinjauan Geografis Terhaadap Upaya Pengembangan Kawasan Obyek

Wisata Goa Lawa Di Kecamatan Karangreja Kabupaten Purbalingga. Semarang: Skripsi Unnes.

Wiseza, F. C. (2017). Faktor-Faktor Yang Mendukung Pengembangan Obyek Wisata Bukit Khayangan Di Kota Sungai Penuh Provinsi Jambi. Nur El-Islam, 4(1), 89-106.

Wolah, F. F. (2016). Peranan Promosi Dalam Meningkatkan Kunjungan Wisatawan Di Kabupaten Poso. Acta Diurna, 5(2).

Yoeti, O. (1998). Pengantar Ilmu Pariwisata. Bandung: Penerbit Angkasa. 